\title{
REPRODUCIBILITY OF OPTIC NERVE HEAD TOPOGRAPHIC MEASUREMENTS WITH THE GLAUCOMA-SCOPE
}

\author{
YVES LACHKAR ${ }^{1,2}$ and HOWARD $\mathrm{COHN}^{1}$ \\ Paris, France
}

\begin{abstract}
SUMMARY
Purpose: Glaucoma is an optic neuropathy in which optic nerve changes are important in diagnosis and progression, because the visual field may remain normal even while the optic nerve is undergoing significant damage. Accurate methods to objectively document the appearance of the optic nerve are necessary. In order for an optic disc imaging system to be clinically useful for detecting change, its reproducibility must be established.

Methods: We measured the reproducibility of duplicate measurements in 59 eyes of 31 consecutive patients, grouped into glaucoma subjects $(n=29)$ and eyes with glaucoma $(n=30)$, with the 3.10 OIS Glaucoma-Scope. In order to simulate two visits on one day, sets of three optic disc images were obtained first, followed by a repeat set, and the best disc images of each (chosen by the computer) were compared.

Results: The coefficients of variation of duplicate measurements for glaucoma suspects and patients with glaucoma were respectively: vertical cup/disc (c/d) ratio, $6.3 \%$ and $3.47 \%$; horizontal c/d ratio, $4.61 \%$ and $2.97 \%$; c/d area, $3.29 \%$ and $1.37 \%$; cup area, $1.82 \%$ and $1.72 \%$; mean position (MP) disc, $13.3 \%$ and $10.42 \%$; MP total, $10.1 \%$ and $13.2 \%$. For three eyes the examination was not possible (opacification of posterior capsule, miosis).

Conclusion: These results suggest that the 3.10 version of the OIS Glaucoma-Scope allows reproducible measurements in living eyes.
\end{abstract}

The analysis and detection of changes in the topography of the optic nerve head is an important parameter in the diagnosis and treatment of patients with glaucoma. The Glaucoma-Scope (Ophthalmic Imaging System, Sacramento, CA) is a computerised

From: ${ }^{1}$ Rothschild Eye Foundation, Paris, France; ${ }^{2}$ Glaucoma Institute, Saint Joseph Hospital, Paris, France.

Correspondence to: Yves Lachkar, Glaucoma Institute, Saint Joseph Hospital, 3 ter rue Pierre Larousse, F-75014 Paris, France. Tel: +33144123420. Fax: +33144123285. optic nerve analyser based on a technique of computed raster-stereography. ${ }^{1,2}$ Recently automated instruments have been developed to quantitatively assess optic nerve head topography using stereophotogrammetry, ${ }^{3,4}$ or laser tomographic scanning. ${ }^{5-7}$ Different studies have documented that morphological changes in the optic nerve and nerve fibre layer precede glaucomatous visual field loss. ${ }^{8-10}$ In order for an optic disc imaging system to be clinically useful in detecting change, its reproducibility must be established.

\section{MATERIALS AND METHODS}

The Glaucoma-Scope consists of an optical head mounted on a slit lamp assembly. The optical head includes the raster pattern projection system and a video camera to capture images. Data are saved immediately on a hard disc and later archived to an optical laser disc where they can be easily accessed. The minimum necessary pupillary diameter following pharmacological mydriasis in the study was $4.0 \mathrm{~mm}$.

A single operator obtained three images from each eye. The operator can control image focus, line focus and illumination independently. When optimal alignment and focus were achieved the image was captured by pressing a button near the joystick. The computer selected a single image for processing based on the quality of focus and line contrast.

Approximately 25 parallel horizontal dark and light pairs are projected at an angle of $9^{\circ}$ to the optic nerve head $(\mathrm{ONH})$ using near-infrared light $(750$ $\mathrm{nm})$. As the lines pass over the surface of the ONH they are deflected proportional to the depth of the surface. A video image records these deflections and computer algorithms translate them into depth numbers computed from 9100 real data points. The reference surface for the depth measurements is defined by linear interpolation of data falling in two vertical $50 \mu \mathrm{m}$ columns placed $350 \mu \mathrm{m}$ nasal and temporal to the disc margin. 


\section{DEPTH 30.03.94 Frame 1}



Fig. 1. Glaucoma-Scope: grey scale and numerical displays.

For the patient's first examination, the operator selected a reference point for future image registration, and outlined the disc margin ( 8 points) and major vessels to provide landmarks on the printout. The disc border was defined as the inner margin of Elschning's ring. The margin and vessel drawings do not affect data calculation. ${ }^{11}$ Computer algorithms perform a best fit analysis on data in an area subtending $4^{\circ}$ surrounding the reference point to register the current and baseline images.
At subsequent examinations, the operator selected a point location on the current image that was near the previously selected reference point to orient the computer, the margin was not redrawn and the computer program then performed a best fit analysis to register the current and baseline images. Both translation and rotation corrections were made. An overlay of the disc margin and vessel information was automatically superimposed on the new image. Results are presented in a grey scale (Fig. 1). 

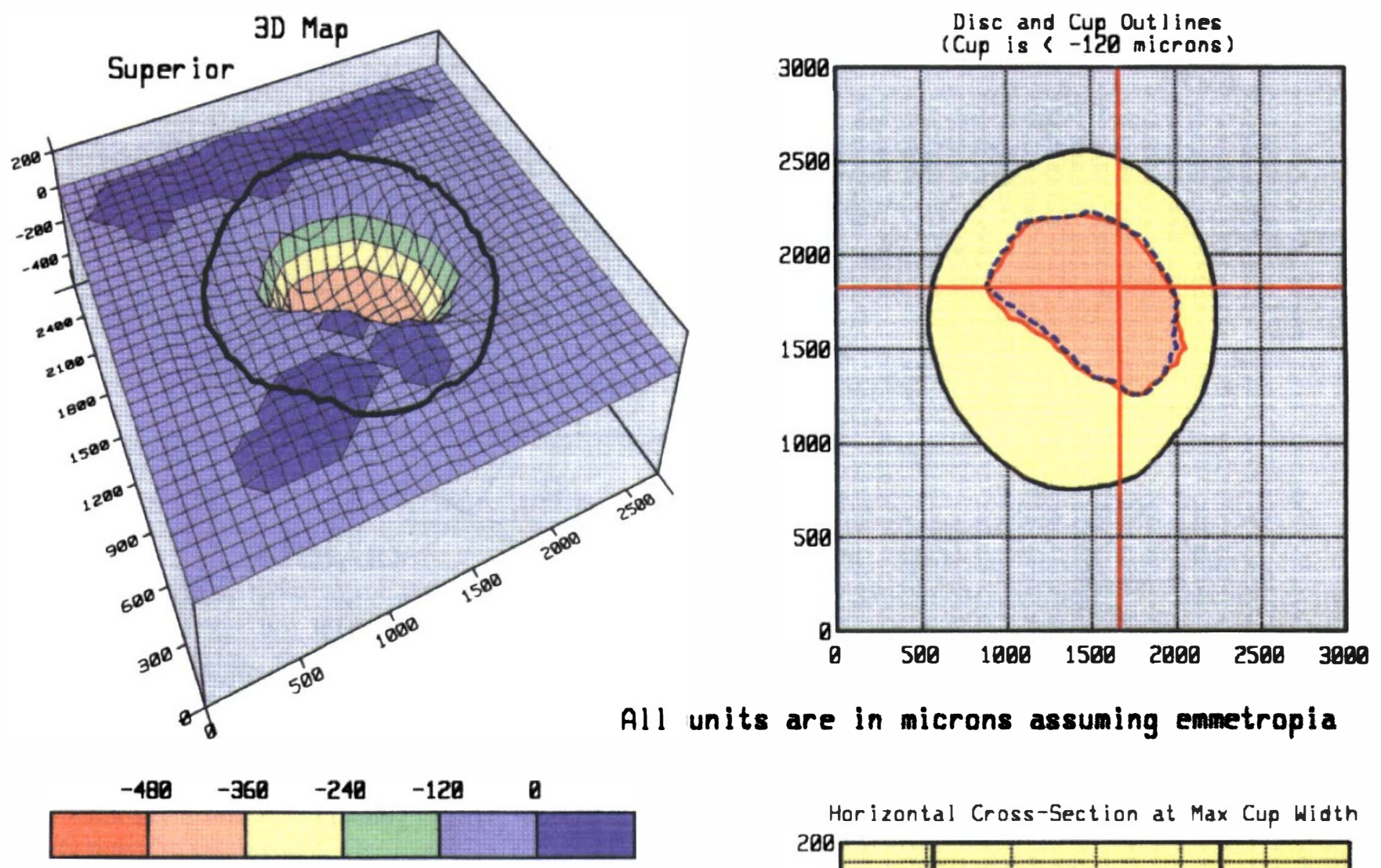

\begin{tabular}{|c|c|c|}
\hline & CURRENT & PREVIOUS \\
\hline Date & 32.09 .94 & 33.60 .94 \\
\hline Analyois & 4 & 3 \\
\hline Frame & 1 & 9 \\
\hline CD Ratio Kert. & 0.49 & 0.49 \\
\hline CD Ratio Horiz. & 0.65 & 0.66 \\
\hline CppDlec Aree Ratlo & 0.31 & 8. 31 \\
\hline Mex Dlec Dien Vert & $1, \mathrm{Bgg}$ & $1,8: 9$ \\
\hline Nax Dlac Dlan Horiz & 1,691 & 1,691 \\
\hline Dise Area (eq. D) & 2.325 & 2.35 \\
\hline ap fres (eq. In) & 0.732 & 0.719 \\
\hline IP Dise & -122.1 & -122.4 \\
\hline rP Total Reglon & -39.1 & -34.5 \\
\hline Rx Sphere & +60.50 & +60.50 \\
\hline Dex Cylinder & $-2.25 \times 15$ & $-60.25 \times 165$ \\
\hline
\end{tabular}

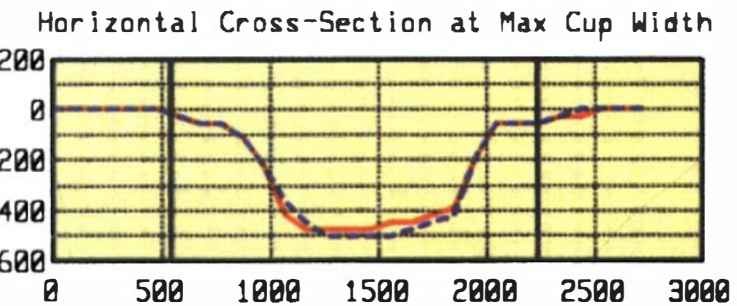

Red refers to current analys is (solid)

Blue refers to previous analysis (dashed)
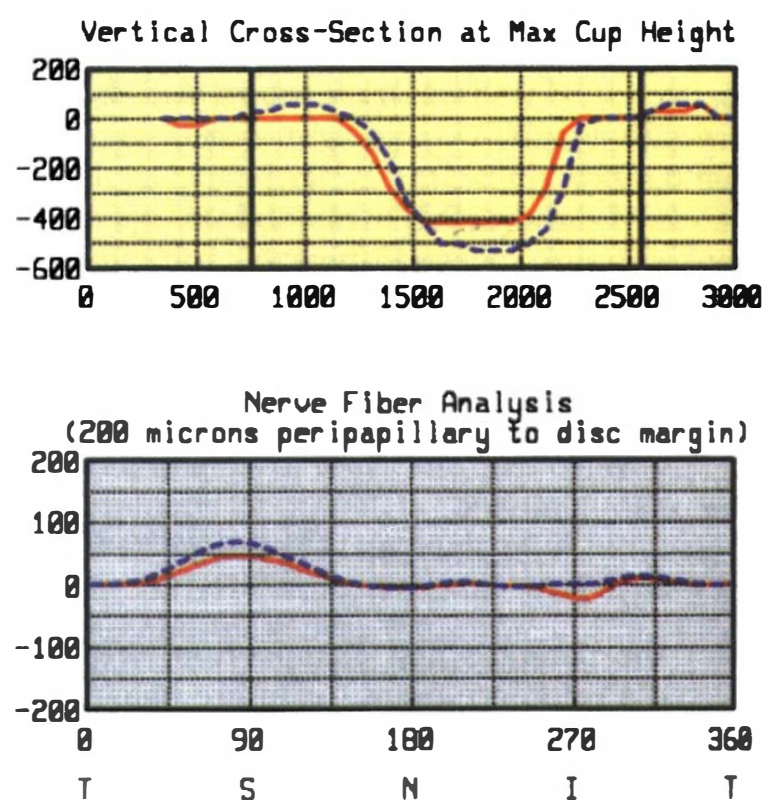

Fig. 2. Glaucoma-Scope: three-dimensional image. 
Numerical values were represented on the printout with each cell representing the average of an area $69 \times 138 \mu \mathrm{m}$ in size. On subsequent visits, depth measurements are automatically compared with measurements made at the initial visit, and a map generated showing any change in depth values (of $<50 \mu \mathrm{m}$ : threshold of the test).

Version 3.10 of the Glaucoma-Scope also presents a three-dimensional image (Fig. 2) with the calculation of different ratios and measurements: vertical cup/disc (c/d) ratio, horizontal c/d ratio, c/d area ratio, cup area (in $\mathrm{mm}^{2}$ ). The optic cup area is defined as the area inside the disc margin $120 \mathrm{~mm}$ below the reference level. The mean position of the disc (MP disc) is also calculated corresponding to the average of all depth measurements within the disc. The mean position of the total region (MP total) is the average of all depth measurements on the topography map. Results from two visits are also compared in the report with the difference in depth reported in both numerical and grey scale. In the present study version 3.10 was used and correction made by the computer for refraction to calculate optic disc size.

This study was performed to evaluate the reproducibility of measurements performed in routine examinations of consecutive suspects or glaucoma patients. We measured the reproducibility of duplicate measurements in 59 eyes of 31 consecutive patients who were divided into glaucoma suspects and patients with chronic glaucoma. For three eyes the examination was not possible for the following reasons: miosis (1 case), large cup (1 case) and opacification of posterior capsule (1 case). In group 1 (glaucoma suspects) there were 15 patients ( 7 women and 8 men) with a mean age of 55 years (range 24-74 years, SD 19 years). In group 2 (chronic glaucoma) there were 16 patients ( 7 women and 9 men) with a mean age of 56 years (range $38-80$ years, SD 13 years). The mean refraction was +0.5 dioptre in group 1 (range -6 to +2.75 ) and +0.9 dioptre in group 2 (range -2.25 to +2.25 ). The age and mean refraction were not statistically different between the two groups $(p>0.90)$.

Chronic glaucoma was defined as intraocular pressure (IOP) more than $22 \mathrm{mmHg}$ with visual field defects (a cluster of three or more non-edge points in a location typical for glaucoma at two consecutive Humphrey 24-2 fields). Suspects had abnormal cupping of the optic disc or an IOP of more than $22 \mathrm{mmHg}$ but without visual field defects (Humphrey 24-2). In group 1 (glaucoma suspects) there were 2 eyes with mild cataract, 9 eyes with ocular hypertension (IOP more than $21 \mathrm{mmHg}$ with normal optic disc and visual field) and 3 eyes with large cups (c/d ratio greater than 0.6 with a normal visual field and IOP). Two eyes had a peripheral iridotomy with a borderline IOP and one patient was suspected of having juvenile glaucoma (borderline IOP, normal visual field and familial history of glaucoma). In group 2 (chronic glaucoma) there were 4 pseudophakic eyes. Four eyes had had a trabeculectomy and 4 had had a trabeculoplasty. Five eyes were treated with two drugs including adrenergic drugs, 5 with miotics and 17 with a beta-blocker. Despite dilatation with tropicamide and phenylephrine, analysis was not possible in 2 eyes: in 1 because of miosis and in 1 because of pseudophakia (despite YAG laser capsulotomy an analysis was not possible).

To determine measurement variability two visits were simulated for each subject in the following manner. Three consecutive images were acquired on the Glaucoma-Scope for each eye. These measurements were assigned to visit 1 . Only minor adjustments for alignment were made between images. after a break of $>1$ minute, three more consecutive images were acquired by the same operator and assigned to visit 2 . Between visits 1 and 2 , the Glaucoma-Scope focus, alignment and illumination were reset to random positions. The computer selected the best image of each visit based on the best focus of the projected horizontal lines over the optic nerve head, for processing and match testing. The reproducibility of the measurements was evaluated by computing the mean, range, average, SD and coefficient of variation $(\mathrm{CV}$; SD divided by the mean). The $\mathrm{CV}$ is one statistical method of adjusting the variability estimate (SD) for the underlying size of the variable being measured. It is assumed that the $\mathrm{CV}$ permits comparison of variations in samples independently of their means, but in some cases this is not true and the CV may not serve its purpose. ${ }^{12}$ However, we used this parameter because it is straightforward and enables comparison of our results with those of other investigators. As the disc area did not change in the results between the two visits, this parameter was not evaluated in the study. As values were normally distributed we used a Student's $t$-test for the statistical analysis.

\section{RESULTS}

Values of the median, mean, range, SD and CV are given in the Table I. The CVs in duplicate measurements for glaucoma suspects and patients with glaucoma were respectively: vertical cup/disc ratio (c/d), $6.3 \%$ and $3.47 \%$; horizontal c/d ratio, $4.61 \%$ and $2.97 \%$; c/d area, $3.29 \%$ and $1.35 \%$; cup area, $1.82 \%$ and $1.72 \%$; MP disc, $13.3 \%$ and $10.42 \%$; and MP total region, $10.1 \%$ and $13.2 \%$. We found a statistically significant difference between the two groups for every parameter tested. This was more significant for the c/d vertical, c/d area, cup area, MP 
Table I. Coefficients of variation (CV) of optic disc parameters

\begin{tabular}{|c|c|c|c|c|}
\hline & \multicolumn{2}{|c|}{ Glaucoma suspects $(n=29)$} & \multicolumn{2}{|c|}{ Glaucoma $(n=30)$} \\
\hline & Mean $\pm S D$ & CV\% & Mean $\pm S D$ & $\mathrm{CV} \%$ \\
\hline $\begin{array}{l}\text { Vertical c/d ratio } \\
\text { Median } \\
\text { Range } \\
\text { Average } \\
\text { SD }\end{array}$ & $\begin{aligned} 0.54 & \pm 0.024 \\
0.3-0.72 & \pm 0-0.14 \\
0.5069 & \pm 0.0233 \\
0.122 & \pm 0.077\end{aligned}$ & $\begin{array}{l}4.4 \\
0-20 \\
4.49 \\
6.3\end{array}$ & $\begin{aligned} 0.69 & \pm 0.005 \\
0.4-0.28 & \pm 0-0.18 \\
0.77 & \pm 0.0109 \\
0.2013 & \pm 0.007\end{aligned}$ & $\begin{array}{l}0.96 \\
0-2 \\
1.84 \\
3.47\end{array}$ \\
\hline $\begin{array}{l}\text { Horizontal c/d ratio } \\
\text { Median } \\
\text { Range } \\
\text { Average } \\
\text { SD }\end{array}$ & $\begin{aligned} 0.715 & \pm 0.01 \\
0.21-0.86 & \pm 0-0.09 \\
0.614 & \pm 0.01 \\
0.245 & \pm 0.1131\end{aligned}$ & $\begin{array}{c}1.39 \\
0-10.46 \\
1.62 \\
4.61\end{array}$ & $\begin{aligned} 0.75 & \pm 0.05 \\
0.21-0.99 & \pm 0.01-0.14 \\
0.717 & \pm 0.0103 \\
0.179 & \pm 0.0532\end{aligned}$ & $\begin{array}{c}7.14 \\
4.76-14.4 \\
1.53 \\
2.97\end{array}$ \\
\hline $\begin{array}{l}c / d \text { area } \\
\text { Median } \\
\text { Range } \\
\text { Average } \\
\text { SD }\end{array}$ & $\begin{aligned} 0.33 & \pm 0.01 \\
0.14-0.59 & \pm 0-0.09 \\
0.337 & \pm 0.01 \\
0.18235 & \pm 0.06\end{aligned}$ & $\begin{array}{c}3.03 \\
0-15.25 \\
2.96 \\
3.29\end{array}$ & $\begin{aligned} 0.53 & \pm 0.015 \\
0.3-0.71 & \pm 0-0.07 \\
0.514 & \pm 0.027 \\
0.155 & \pm 0.021\end{aligned}$ & $\begin{array}{l}3.65 \\
0-9.85 \\
5.25 \\
1.35\end{array}$ \\
\hline $\begin{array}{l}\text { Cup area } \\
\text { Median } \\
\text { Range } \\
\text { Average } \\
\text { SD }\end{array}$ & $\begin{aligned} 0.91 & \pm 0.012 \\
0.063-2.085 & \pm 0.01-0.1 \\
0.918 & \pm 0.07 \\
0.568 & \pm 0.1034\end{aligned}$ & $\begin{array}{c}1.31 \\
1.58-9.11 \\
0.76 \\
1.82\end{array}$ & $\begin{aligned} 1.091 & \pm 0.05 \\
0.458-2.581 & \pm 0.004-0.1 \\
1.228 & \pm 0.0145 \\
0.51 & \pm 0.0088\end{aligned}$ & $\begin{array}{c}4.58 \\
0.87-5.81 \\
1.4 \\
1.72\end{array}$ \\
\hline $\begin{array}{l}\text { MP disc } \\
\text { Median } \\
\text { Range } \\
\text { Average } \\
\text { SD }\end{array}$ & $\begin{aligned}-95.9 & \pm 9.65 \\
+6.9-223 & \pm 2.6-36.9 \\
-99.85 & \pm 11.92 \\
69.87 & \pm 9.36\end{aligned}$ & $\begin{array}{l}10.06 \\
4-16 \\
11.93 \\
13.3\end{array}$ & $\begin{aligned}-171.5 & \pm 8.1 \\
-30-253 & \pm 0.3-38.8 \\
-170.48 & \pm 10.15 \\
74.775 & \pm 8.835\end{aligned}$ & $\begin{array}{r}4.72 \\
1-15 \\
5.95 \\
10.42\end{array}$ \\
\hline $\begin{array}{l}\text { MP total } \\
\text { Median } \\
\text { Range } \\
\text { Average } \\
\text { SD }\end{array}$ & $\begin{aligned}-29.85 & \pm 3.65 \\
5.8-101 & \pm 0.5-12 \\
-37.34 & \pm 3.58 \\
30.18 & \pm 3.05\end{aligned}$ & $\begin{array}{l}12.2 \\
8.62-12 \\
12.26 \\
10.1\end{array}$ & $\begin{aligned}-68 & \pm 3.6 \\
-11-97 & \pm 0.5-14 \\
-65.53 & \pm 5.56 \\
34.07 & \pm 5.21\end{aligned}$ & $\begin{array}{c}5.29 \\
4.54-14.4 \\
8.48 \\
13.2\end{array}$ \\
\hline
\end{tabular}

c/d, cup/disc; MP, mean position.

disc and MP total region $(p<0.001)$ and than for the $c / d$ horizontal $(p<0.05)$.

\section{DISCUSSION}

Clinical examination of the optic disc is subjective and interpretations are often inconsistent, even among expert observers. ${ }^{13-15}$ Methods of optic disc analysis include disc photography, planimetry, stereophotogrammetry, Humphrey disc analyser, Rodenstock analyser, Heidelberg Retina Tomograph and Glaucoma-Scope.

Planimetry is a method of examining the $\mathrm{ONH}$ that provides only one-dimensional and area measurements. The $\mathrm{CV}$ reported by Jonas ${ }^{16}$ was $3 \%$ when the area of the optic disc was defined 10 times in each of 10 photographs of 10 normal discs. The CV increased to $11 \%$ for small discs. Reproducibility values for rim area have not been reported with this method. Studies have been performed to examine the reproducibility of repeated evaluation of one photograph or comparison of planimetry with automated devices, ${ }^{17,18}$ but these do not take into account the variability of different photographs of the same disc.

Stereophotogrammetry is a method in which stereophotographs are used to measure objects in three-dimensional space. Stereophotographs of the optic disc are taken from two camera positions with parallel optic axes. Rosenthal et al. ${ }^{19}$ calculated the $\mathrm{CV}$ of photogrammetric measurements of optic disc cupping in three eyes of 3 subjects (diagnoses were not given) and found values of $3.1 \%$ for cup depth, $6.1 \%$ for cup area, and $7.8 \%$ for cup volume. Takamoto and Schwartz ${ }^{20}$ in 10 normal eyes found a CV of $4.6 \%$ for the cup depth/disc area, $5.2 \%$ for cup area/disc area and $7.7 \%$ for cup volume/disc area. The CV\% for optic cup volume varies between $4.5 \%$ and $8.3 \%$ depending on the group of patients. Our CVs for the c/d area (3.03\% and 3.65\%) and cup area $(1.31 \%$ and $4.58 \%)$ are equivalent to or less than that observed with photogrammetry. Optic disc cup measurements by stereophotogrammetry and the Glaucoma-Scope have been compared previously, ${ }^{21}$ showing similar measurements of the cup area: $0.272 \pm 0.071$ with the Glaucoma-Scope and $0.287 \pm 0.063$ with photogrammetry.

The Humphrey disc analyser uses a standard fundus camera and digitisation of simultaneous stereo images. An operator is also required to mark the disc edge at eight or more locations. It then develops an oval or egg-shaped approximation of the disc margin. The operator-marked disc edge is processed to obtain the final disc edge, which is considered the 'reference zero'. The depth or 
Table II. Comparison of mean standard deviation of individual depth measurements by different image analysis systems

\begin{tabular}{|c|c|c|c|}
\hline Instrument & Reference & $\begin{array}{c}\text { Mean SD } \\
\text { of individual } \\
\text { depth } \\
\text { measurements } \\
(\mu \mathrm{m})\end{array}$ & $\begin{array}{c}95 \% \\
\text { CI for } \\
\text { individual cell }\end{array}$ \\
\hline $\begin{array}{l}\text { Confocal SLO } \\
\text { (Carl Zeiss) }\end{array}$ & Cioffi $e t a l^{27}$ & $\mathrm{NR}$ & 102 \\
\hline $\begin{array}{l}\text { Confocal SLO: } \\
\text { HRT } \\
\text { (Heidelberg) }\end{array}$ & $\begin{array}{l}\text { Dreher et al. } \\
\text { Chauhan } \text { et }^{7} \text { al. }^{28} \\
\text { Weinreb et al } \\
\text { Lusky et al. } \\
{ }^{29}\end{array}$ & $\begin{array}{c}38.7-49.4 \\
25.94-31.20 \\
22.5-40.2 \\
30.1-31.8\end{array}$ & $\begin{array}{l}\text { NR } \\
\text { NR } \\
\text { NR } \\
\text { NR }\end{array}$ \\
\hline $\begin{array}{l}\text { Glaucoma-scope } \\
\text { (OIS) }\end{array}$ & $\begin{array}{l}\text { Hoskins et al. }{ }^{11} \\
\text { Pendergast and } \\
\text { Shields }^{26}\end{array}$ & $\begin{array}{c}12.61 \\
3.98-14.09\end{array}$ & $\begin{array}{c}50.44 \\
37.6-48.2\end{array}$ \\
\hline
\end{tabular}

NR, not reported.

elevation at 400-600 approximately equally spaced points on and around the optic head are then computed. The reproducibility of the Humphrey disc analyser for normal eyes is $0.066 \mathrm{~mm}^{2}$ for the rim and $0.030 \mathrm{~mm}^{2}$ for the disc area. ${ }^{22}$ The CV in this study for the rim area was $3.33 \%$ for normal eyes and $1.69 \%$ for glaucomatous eyes.

The Rodenstock analyser is also based on computerised analysis of stereoscopic images. The machine determines the cup margin with points that are 150 $\mu \mathrm{m}$ posterior to the disc margin determined by the operator. The digital input comes directly from a stereoscopic video camera, and is obtained while projecting two sets of seven evenly spaced lines on the ONH. Depth values are calculated at 140 points along each of the 14 vertical stripes and a surface interpolated between the stripes. The mean $\mathrm{CV}$ for multiple examinations in controls has been reported to vary from $5.8 \%$ to $9.2 \%$ for the c/d ratio, $5.6 \%$ to $17 \%$ for neuroretinal rim area and from $7.1 \%$ to $24.2 \%$ for cup volume. ${ }^{12,17,23,24}$

The Heidelbeg Retina Tomograph (HRT) analyses the $\mathrm{ONH}$ with an image series obtained from 32 transverse optical section images taken at consecutive height planes over a scan depth of 0.5 to $4 \mathrm{~mm}$ and with a scan angle of $10^{\circ}$ to $20^{\circ}$ in $5^{\circ}$ steps. Each image series is analysed to create a topographic map containing $256 \times 256$ picture elements (65536 pixels) with a field of view of $10^{\circ}$. The margin of the $\mathrm{ONH}$ also has to be defined by the operator. The standard deviation for triple measurements of the rim area in control eyes reported by Rohrscheider et al. ${ }^{25}$ is $0.040 \mathrm{~mm}^{2}$ with this machine. The mean CV was $4.3 \%$ and $3.6 \%$ respectively for the neuroretinal rim and cup volume in this study. In our study the $\mathrm{CV}$ for the cup area varied from $1.31 \%$ to $4.58 \%$. However, the principle of laser scanning tomography is different and based on three-dimensional measurements.

Reproducibility of measurements with the Glaucoma-Scope has also previously been studied with the calculation of variability of depth measurements of a pixel. Hoskins et al. ${ }^{11}$ found a standard deviation of individual pixel results of $15.42 \mu \mathrm{m}(15.11 \mu \mathrm{m}$ for the total population, $15.11 \mu \mathrm{m}$ for healthy discs and $15.57 \mu \mathrm{m}$ for glaucomatous discs). The range $\pm 2 \mathrm{SD}$ for mean single pixels was $61.68 \mu \mathrm{m}(60.44 \mu \mathrm{m}$ for healthy discs and $62.28 \mu \mathrm{m}$ for glaucomatous discs) but the number of measurements in this study was five for each visit. Pendergast and Shields ${ }^{26}$ found that the standard deviation in regions of potential clinical interest ranged from $3.98 \mu \mathrm{m}$ to $14.09 \mu \mathrm{m}$ and the $95 \%$ confidence interval for individual cells ranged from 37.6 to $48.2 \mu \mathrm{m}$. These results were found with an earlier version (3.09) of the software that did not take into account magnification errors related to refraction and gave only the numerical and grey-scale results.

Cioffi et $a l .{ }^{27}$ reported with the confocal scanning laser ophthalmoscope (Carl Zeiss) a confidence interval for depth measurements for the entire image of $102 \mu \mathrm{m}$ in 10 normal volunteers. Dreher et $a l^{7}$ using the HRT (confocal laser tomographic scanner) reported that the standard deviation of a single height measurement in 8 normal subjects was $38.7 \mu \mathrm{m}$ and $42.6 \mu \mathrm{m}$ for the peripapillary retina and the area within the optic nerve, respectively. For 8 glaucoma patients these values were $41.2 \mu \mathrm{m}$ and $49.4 \mu \mathrm{m}$ respectively. Chauhan et al ${ }^{28}$ reported a standard deviation equivalent test-retest variability in 30 patients with glaucoma and 30 normal controls subjects of $31.20 \mu \mathrm{m}$ and $25.94 \mu \mathrm{m}$ respectively.

Tables II and III provide a review of previous articles studying reproducibility of topographical analysis of various optic disc analysers. However, comparison of studies evaluating the reproducibility of various instruments is limited because these devices measure depth by varying techniques and because methods of analysis and size of pixel in these studies vary. For example, with the HRT 32 different focal plane optical sections are obtained with a resolution of $256 \times 256$ pixels of $15 \times 15 \mu \mathrm{m}$, while with the Glaucoma-Scope there are only 25 lines projected with 350 points per lines with a pixel size of $69 \times 138 \mu \mathrm{m}$. The results reported in this study are not therefore necessarily comparable across instruments. Most of the studies analyse the intra-operator variability, ${ }^{11,17,22,23,25-27,29,30}$ but the time period between two measurements for the reproducibility study is variable: 30 seconds, ${ }^{26} 1$ minute, ${ }^{11} 15$ minutes, ${ }^{30} 1-6$ hours $^{28}$ or two separate days. ${ }^{7}$

In a clinical setting inter-observer variability could also play a role, but this factor was not evaluated. However, in this study alignment and illumination were reset to random positions between the two visits, but the same operator using the machine for several months obtained all images. With other machines a learning curve has been suggested by 
Table III. Comparison of the coefficients of variation of optic disc parameters by different image analysis systems in comparison with this study

\begin{tabular}{|c|c|c|c|c|c|c|c|}
\hline \multirow[b]{2}{*}{$\begin{array}{l}\text { Instrument } \\
\text { parameter }\end{array}$} & \multirow[b]{2}{*}{ Reference } & \multirow[b]{2}{*}{ Number } & \multicolumn{5}{|c|}{ Coefficient of variation: \% (range) } \\
\hline & & & $\begin{array}{l}\text { Vertical } \\
\text { c/d ratio }\end{array}$ & $\begin{array}{l}\text { Horizontal } \\
\text { c/d ratio }\end{array}$ & $\underset{\left(\mathrm{mm}^{2}\right)}{\operatorname{Rim} \text { area }}$ & $\begin{array}{c}\text { Cup } \\
\text { volume }\end{array}$ & $\underset{\left(\mathrm{mm}^{2}\right)}{\text { Cup area }}$ \\
\hline $\begin{array}{l}\text { ONHA } \\
\text { (Rodenstock) }\end{array}$ & $\begin{array}{l}\text { Shields et al. } \\
\text { Caprioli } \text { et } \text { al. }^{23}\end{array}$ & $\begin{array}{l}n=10 \\
n=7 \\
\text { Glc }=7\end{array}$ & $\begin{array}{c}7.8(4.8-15.6) \\
5.8(1.8-23) \\
3.9(1.4-16)\end{array}$ & $\begin{array}{l}9.2(6.7-32.8) \\
7.9(3.2-13) \\
3.3(0.7-6.8)\end{array}$ & $\begin{array}{l}6.1(2.8-11.5) \\
5.6(3.4-10) \\
7.5(4.2-17)\end{array}$ & $\begin{array}{c}24.2(8.8-44.6) \\
7.1(3.4-21) \\
7.6(4.1-14)\end{array}$ & $\begin{array}{l}\text { NR } \\
\text { NR } \\
\text { NR }\end{array}$ \\
\hline $\begin{array}{l}\text { Humphrey } \\
\text { analyser }\end{array}$ & Dandona et $_{\text {al. }}{ }^{22}$ & $\begin{array}{l}n=10 \\
\text { Glc }=10\end{array}$ & $\begin{array}{l}\text { NR } \\
\text { NR }\end{array}$ & $\begin{array}{l}\text { NR } \\
\text { NR }\end{array}$ & $\begin{array}{l}3.33(1.44-4.90) \\
1.69(0.52-4.92)\end{array}$ & $\begin{array}{l}\text { NR } \\
\text { NR }\end{array}$ & $\begin{array}{l}\text { NR } \\
\text { NR }\end{array}$ \\
\hline $\begin{array}{l}\text { Confocal SLO: } \\
\text { HRT } \\
\text { Heidelberg }\end{array}$ & $\begin{array}{l}\text { Kruse et al. } \\
\text { Rohrschneider et al. }\end{array}$ & $\begin{array}{l}n=8 \\
n=8 \\
\text { Glc suspects }=8 \\
\text { Glc }=8\end{array}$ & $\begin{array}{l}\text { NR } \\
\text { NR }\end{array}$ & $\begin{array}{l}\text { NR } \\
\text { NR }\end{array}$ & $\begin{array}{c}\text { NR } \\
5.2(0.3-12.3) \\
6(1.5-9.5) \\
5.1(1.0-8.8)\end{array}$ & $\begin{array}{c}9.5(3.9-18.2) \\
11(1.8-41.8) \\
5.00(1.2-9.8) \\
5.1(1.9-9.3)\end{array}$ & $\begin{array}{c}\mathrm{NR} \\
9.2(0.4-36.2) \\
2.6(0.4-9.4) \\
3.1(0.5-5.5)\end{array}$ \\
\hline $\begin{array}{l}\text { Glaucoma- } \\
\text { Scope }\end{array}$ & Present study & $\begin{array}{l}\text { Glc suspects }=29 \\
\text { Glc }=32\end{array}$ & $\begin{array}{l}4.4(0-20) \\
0.96(0-2)\end{array}$ & $\begin{array}{c}1.39(0-10.46) \\
7.14(4.76-14.41)\end{array}$ & $\begin{array}{l}3.03(0-15.25) \\
3.65(0-9.85)\end{array}$ & $\begin{array}{l}\text { NR } \\
\text { NR }\end{array}$ & $\begin{array}{l}1.31(1.58-9.11) \\
4.58(0.87-5.81)\end{array}$ \\
\hline
\end{tabular}

Glc, glaucoma; NR, not reported.

the finding that more experienced operators achieve a higher level of reproducibility as compared with less-experienced operators. ${ }^{23}$ For reproducibility studies when a short time was chosen between measurements the operator would be aware of what a good disc picture should look like and this would influence the quality of the pictures recorded thereafter. The present version of the GlaucomaScope helps the operator to obtain good images and the best image is selected by the computer. Hamzavi et $a l^{31}$ evaluated the inter- and intra-observer variation of the $\mathrm{ONH}$ using the Glaucoma-Scope and demonstrated a good repeatability between observers, but this study was done in a cadaver eye model. The authors also found a greater intraobserver variation at the bottom of the disc $(\mathrm{SD}=$ $40.84 \mu \mathrm{m})$ than along the cup wall $(\mathrm{SD}=25 \mu \mathrm{m})$ and over the neural $\operatorname{rim}(\mathrm{SD}=25 \mu \mathrm{m})$.

In an attempt to simulate routine clinical conditions we only compared two measurements. As this study evaluated the reproducibility of consecutive measurements in glaucoma suspects or glaucomatous patients, we did not reject borderline quality images. It was therefore not possible to select and store the best series of the examination and to later select randomly. As the highest test-retest variability of topographic measurements has previously been found along the cup border and blood vessels ${ }^{4,27-}$ $29,31,32$ we chose only glaucoma suspects or patients with glaucoma. Despite these limitations, reproducibility measurements were judged to be quite acceptable.

A cut-off value of $50 \mu \mathrm{m}$ (chosen by the manufacturers) to detect significant change seems reasonable. However, other factors could influence the calculation of ratios of disc parameters such as the retinal vessel diameter during pulsatile blood flow. Despite these potential errors the GlaucomaScope seems to give acceptable results and the reproducibility of our measurements was in the range of other published reports. Nevertheless the
Glaucoma-Scope gives only two-dimensional parameters and it is necessary to dilate the pupil for image acquisition.

Despite adequate dilatation of the pupil pseudophakic eyes were difficult to analyse because the angle of the beam was too large to avoid capsular opacities. In miosis it is also not possible to perform analysis, reflecting a limitation of this instrument. We did not have patients in our study with high refractive error or aphakia whose eyes could also have been difficult or impossible to analyse.

Assuming that accuracy will be established for this instrument, it is uncertain whether traditional measures, such as c/d ratio and c/d area, will be the optimum measures for the detection and follow-up of glaucoma. However, other parameters such as the mean position of the disc could also be used to estimate the degree of glaucoma damage.

\section{CONCLUSION}

These results suggest that the 3.10 Glaucoma-Scope allows reproducible measurements of optic disc morphology and could be a tool in the follow-up and management of glaucoma or subjects suspected of having glaucoma. Further studies are needed to evaluate the reproducibility of measurements of nerve fibre analysis and the accuracy and ability of the Glaucoma-Scope to detect progression of glaucomatous cupping over time.

The authors have no proprietary interest in the Ophthalmic Imaging System.

We wish to thank Mr Philip Bloom (Consultant Ophthalmologist, Western Eye Hospital, London) for his important contributions to the manuscript.

Presented at the JERMOV meeting, Montpellier, 17 October 1995.

Key words: Computerised optic nerve head analysis, Glaucoma, Glaucoma-Scope, Optic nerve head topography, Raster tomography. 


\section{REFERENCES}

1. Holm O, Krakau CET. A photographic method for measuring the volume of papillary excavations. Ann Ophthalmol 1970;1:327-32.

2. Krakau CET, Torlegard K. Comparison between stereo and slit images photogrammetric measurements of the optic disc. Acta Ophthalmol (Copenh) 1972;50: 863-71.

3. Varma R, Steinmann WC, Spaeth GL, Wilson RP. Variability in digital analysis of optic disc topography. Graefes Arch Clin Exp Ophthalmol 1988;226: 435-42.

4. Dandona L, Quigley HA, Jampel HD. Variability of depth measurements of the optic nerve head and peripapillary retina with computerised image analysis. Arch Ophthalmol 1989;107:1786-92.

5. Kruse FE, Burk ROW, Völcker HE, et al. Reproducibility of topographic measurements of optic nerve head with laser tomographic scanning. Ophthalmology 1989;96:1320-4.

6. Rohrschneider K, Burk ROW, Kruse FE, Völcker HE. Reproducibility of the optic nerve head topography with a new laser tomographic scanning device. Ophthalmology 1994;101:1044-9.

7. Dreher AW, Tso PC, Weinreb RN. Reproducibility of topographic measurements of the normal and glaucomatous optic nerve head with the laser tomographic scanner. Am J Ophthalmol 1991;111:221-9.

8. Caprioli J. Recommendations for future studies. J Glaucoma 1993;2:29-30.

9. Montgomery DMI. Clinical disc biometry in early glaucoma. Ophthalmology 1993;100:52-6.

10. Zeyen TG, Caprioli J. Progression of disc and field damage in early glaucoma. Arch Ophthalmol 1993;111: 62-5.

11. Hoskins HD, Hetherington J, Glenday M, Samuels S, Verdooner S. Repeatability of the Glaucoma-Scope measurements of the optic nerve topography. J Glaucoma 1994;3:17-27.

12. Shields MB, Martone JF, Shelton AR, Ollie A, MacMillan J. Reproducibility of optic nerve head topographic measurements with optic nerve head analyser. Am J Ophthalmol 1987;104:581-6.

13. Lichter PR. Variability of expert observers in evaluating the optic disc. Trans Am Ophthalmic Soc 1976;74: 532-72.

14. Tielsch JM, Katz J, Quigley HA, et al. Intraobserver and interobserver agreement in measurement of optic disc characteristics. Ophthalmology 1988;95:350-6.

15. Varma R, Steinmann WC, Scott IU. Expert agreement in evaluating the optic disc for glaucoma. Ophthalmology 1992;99:215-21.

16. Jonas JB. Biomorphometre des Nervus opticus. Stuttgart: Enke, 1989.

17. Mikelberg FS, Douglas GR, Schulzer M, et al. The correlation between cup-disc ratio, neuroretinal rim area, and optic disc area measured by the video ophthalmograph and clinical measurement. Am J Ophthalmol 1986;101:7.
18. Varma R, Douglas GR, Steinman WC, et al. A comparative evaluation of three methods of analysing optic disc photography. Ophthalmic Surg 1989;20:813.

19. Rosenthal AR, Kottler MS, Donaldson DD, Falconer DG. Comparative reproducibility of the digital photogrammetric procedure utilising three methods of stereophotography. Invest Ophthalmol Vis Sci 1977; 16:54-60.

20. Takamoto T, Schwartz B. Reproducibility of photogrammetric optic disc cup measurements. Invest Ophthalmol Vis Sci 1985;26:814-7.

21. Takamoto T, Netland PA, Schwartz B. Comparison of measurements of optic disc cup by Glaucoma-Scope and stereophotogrammetry. Invest Ophthalmol Vis Sci 1994; 35(Suppl):1348.

22. Dandona L, Quigley HA, Jampel HD. Reliability of optic nerve head topographic measurements with computed images analysis. Am J Ophthalmol 1989; 108:414-21.

23. Caprioli J, Klingbell U, Sears M, Pope B. Reproducibility of optic disc measurements with computerised analysis of stereoscopic video images. Arch Ophthalmol 1986;104:1035-9.

24. Shields MB, Tiedeman JS, Miller KN, Higinbotham D, Ollie A. Accuracy of topographic measurements with the optic nerve head analyser. Am J Ophthalmol 1989; 170:273-9.

25. Rohrschneider K, Burk ROW, Völcker HE. Reproducibility of topometric data acquisition in normal and glaucomatous optic nerve heads with the laser tomographic scanner. Graefes Arch Clin Exp Ophthalmol 1993;231:457-64.

26. Pendergast SD, Shields B. Reproducibility of optic nerve head topographic measurements with the OIS Glaucoma-Scope. J Glaucoma 1995;4:169-76.

27. Cioffi GA, Robin AL, Eastman RD, Perell HF, Sarfarazi FA, Kelman SE. Confocal laser scanning ophthalmoscope: reproducibility of optic nerve head topographic measurements with the confocal laser scanning ophthalmoscope. Ophthalmology 1993;100: 57-62,

28. Chauhan BC, LeBlanc RP, McCormick TA, Rogers JB. Test-retest variability of topographic measurements with confocal scanning laser tomography in patients with glaucoma and control subjects. Am J Ophthalmol 1994;188:9-15.

29. Lusky M, Bosem ME, Weinreb R. Reproducibility of optic nerve head topography measurements in eyes with undilated pupils. J Glaucoma 1993;2:104-9.

30. Weinreb R, Lusky M, Bartsch D, et al. Effect of repetitive imaging on topographic measurements of the optic nerve head. Arch Ophthalmol 1993;111:636-9.

31. Hamzavi S, Stewart WC, Jackson GL, Thompson TL. Reproducibility of the Glaucoma-Scope in cadaver eyes. Acta Ophthalmol (Copenh) 1995;73:264-7.

32. Miller E, Caprioli J. Regional long term variability of fundus measurements made with computer image analysis. Am J Ophthalmol 1991;112:171.

33. Mikelberg FS, Wijsman K, Schultzer M. Reproducibility of topographic parameters obtained with the Heidelberg Retina tomograph. J Glaucoma 1993;2:101-3. 